\title{
A Comparative Study of Improving the Efficiency of College Students' English Learning by Audiolingual Method and Total Physical Response Teaching
}

\author{
Qian Wang \\ Inner Mongolia Univerisity for Nationalities \\ Tongliao, China
}

\begin{abstract}
Thanks to the development of Belt and Road Initiative economic policy, there are exchanges between countries and countries from the aspects of science and technology, economic, political and cultural. English as the most popular language in the world, has been playing a vital role in the international community. The main purpose of this article is to study the current situation, and analyze similarities and differences between the Audiolingual Method and Total Physical Response (TPR) to improve the efficiency of college students English learning.
\end{abstract}

Keywords-the Audiolingual Method; TPR; language teaching

\section{INTRODUCTION}

With the progress of science and technology, economic, political and cultural exchanges between countries and countries are closer and the level of social productivity has been improved. English as the most popular language in the world has been playing a vital role in the international community. This essay, based on the Audiolingual Method and TPR, aims to explore similarities and differences of the two methods in terms of their underlying theoretical bases and characteristics, thereby defining for which group of learners they are suitable.

The main goal of English teaching is to train students' comprehensive ability in English learning, especially in the practical use of language. At the same time, it can also make good use of oral communication and clerical communication for students' future work and social life. If good teaching methods can improve the students' autonomous learning ability, and improve the comprehensive cultural quality, but also better for the strategic investment The Belt and Road provides talent reserves. Recently, all colleges and universities in the country carry out the educational reform and the classroom reform comprehensively. For the sake of the new round of demands and competitions, educators can optimize the teaching content reasonably and change the teaching methods to keep pace with the times. English teaching is also the research focus of the educational scholars. How to improve the students' efficiency, how to complete the language output effectively, how to change the classroom atmosphere, and how to arouse the students' enthusiasm and

Project Number: QN2017009 (University Item) participation are the problems that English teachers have been exploring in theory and practice. At present, the problem is that the English class is mostly centered on the teacher's presentation, and the students are passively listening. The situations about the students' weak learning initiative, poor classroom interaction, poor concentration, which leads students not to collect knowledge, absorb knowledge, analyze and solve problems in the critical thinking. In order to adapt to the English foundation of different students, to meet the different culture of professional development, fully embodies the principle of individualized teaching, active participation, hierarchical optimization, classification guidance, overall progress, promote the overall optimization of English teaching and improve English learning, English teachers must establish a reasonable and perfect, suitable for the development of modern economy English teaching mode.

\section{COMPARE AND CONTRAST OF AUDI LINGUAL METHOD AND TPR}

The method of Audiolingual teaching is a kind of teaching method which is based on combine pronunciation with intensive oral drillings of sentence patterns. It is a kind of teaching method formed by means of audiovisual combination on the basis of listening and speaking. It emphasizes auditory perception and recording in certain situations, combined with sentence-based intensive oral training (Wikipedia). The procedure is as follows: first presented to the student model dialogue and then some lines of dialogue so that students repeat, individual repeat or overall repeat. More detailed words, Sentences in each line may be broken down into some words or phrases if necessary. Second, pronunciation, intonation, and fluency will further be emphasized by the teacher. The teacher can correct the pronunciation or grammatical errors that need to be directly and directly known. In contrast, systemic counseling is based on the combination of speech and action, focusing on teaching language through physical activity. Learners must follow a series of orders and then react before they begin to produce verbal reactions (Richards and Rogers, 2001). In the initial stages of the learning phase, errors are allowed. In deepening the language knowledge, teachers should constantly intervene and correct students' errors, and 
more delicate expressions can be made by learners (Wei, 2014).

\section{A. The Definition and Theory of Methods}

In terms of language theory, Audiolingual Method and TPR have their own characteristics. Structural linguistics influenced the Audiolingual approach proposed by American linguists in 1950. The Audiolingual method shows several basic features that differ from TPR. For example, elements in a language are generated linearly in a rule-managed manner. In addition, language samples can be described at any structural level (voice, phoneme, and form). In addition, language learning is considered to be a rigorous system in which pyramids can be structured and phoneme systems lead to morphemeization, which leads to phrases, sentences and sentences. However, James Asher proposed the TPR, which he pointed out that second language learning was similar to that of children's first language acquisition (Richards \& Rodgers, 2001). Specifically, the fact is that in the first language learning process, the baby is likely to respond to the language through the reaction, until enough vocabulary and sentence structure to accumulate (Tian, 2014). Similarly, Asher claims that second language acquisition is a parallel process. Based on the theoretical basis, we discuss the vocabulary of a large part of the grammatical structure and the target language that can be learned from the teacher's mandatory application (Richards \& Rodgers, 2001)

\section{B. The Aims of Learning}

The learning theory of the Audiolingual Method is based on behavioral psychology (Richards \& Rodgers, 2001). To behaviorists, a stimulus can be elicited to trigger a response. Accordingly, some kind of reinforcement then can be produced by the response (Bowen, n.d.). In other words, in order to achieve language learning, learners should respond to a stimulus in correct ways and be positively reinforced (Hall, 2011).Similarly, TPR is also regarded a stimulusresponse view as the learning theory, which is moreover connected with the trace theory of memory in psychology (Richards\& Rodgers, 2001). It is stated that language is seen as echoing extrinsic stimuli that naturally produce responses. Physical responses are the impressive trace in memory (Wei, 2014). The more intensively a memory association is tracked, and the more possible it will be recalled (Richards\& Rodgers, 2001).

\section{The Roles of Learners and the Teacher}

For the Audiolingual approach, learners are treated as recipients of passive language knowledge and respond to stimuli with little chance to control the content, pace, or style of learning (Richards \& Rodgers, 2001). Learners rely almost entirely on mechanical imitation and memory phrases and sentences (Brown, 2006). Teachers are strongly encouraged to encourage and support students, learning English by constantly repeating the correct words, phrases and sentences (Hamer, 2007), but students do not have to understand the meaning of their repetitive content (Richards \& Rodgers, 2001). About TPR, learners are the main listeners and performers. They can understand the meaning of imitation, should not make themselves feel self-conscious, and encourage them to speak in preparation for speech (Richards \& Rodgers, 2001).

The role of teachers in the Audiolingual approach is critical and positive. It should be a teacher-led approach. They control content, learn the speed and monitor the performance of learners (Richards \& Rodgers, 2001). Allow small mother tongue to apply to this method (Brown, 2006). Similarly, the teacher in the TPR play an active and direct role. In addition, teachers decide to teach what, who will simulate and present new materials. (Richards \& Rodgers, 2001)

\section{ADVANTAGES AND DiSADVANTAGES OF THE AUDIOLINGUAL METHOD AND TPR}

The Audiolingual Method has a great influence on learners and teachers. In terms of its advantages, first of all, pronunciation has important significance. It helps learners to improve stress, rhythm, intonation, fluency and accuracy. Secondly, it enables learners to learn from the mistakes via being corrected by the teacher. However, there are several shortcomings in Audiolingual Method. First of all, it is a mechanical learning habit of the formation of the process, ignoring the real environment outside the classroom. However, language acquisition is mainly the result of psychological and mental learning process, rather than the formation of mechanical habits when learners produce speech. Therefore, through this training, it is unrealistic for learners to communicate better with others. In addition, the constant repetition and practice for students may be boring and dissatisfied, which may not be a suitable and effective way for learners to study for a long time.

TPR also has its limitations. Learners seem to be able to use a limited number of words, phrases or sentences in the classroom. Nevertheless, the TPR does not force students to speak before they are ready to speak, and students can be easy to feel more comfortable in a relatively stress-free learning environment.

\section{CONCLUSION}

The basic way and main form of education as well as the core content of quality-oriented education are the foundation of the development of students. Therefore, it is an urgent task for the modern teaching to activate the classroom, improve the sense of life in teaching and explore the effectiveness of classroom teaching. In order to stimulate and cultivate students' interests in learning English and improve students' English learning to enable students to form good learning habits and learning enthusiasm and initiative strategy effectively, implement the training ability of autonomous learning and cooperative spirit of students of the course students should be constructed under the guidance of teachers knowledge, improve skills, honed, active thinking, personality and thinking of the development and expansion of the field of vision.

In the final analysis, Audio lingual Method and TPR have been in vogue for a period of time. These two methods contribute greatly to English teaching. Although phonetics teaching method is rarely used in English teaching as a 
systematic approach, it is of great value for the construction and practice of exercise based activities, dialogue construction and practice. As a result, it helps limited English learners and relatively small help for advanced learners. As a result, TPR pays attention to comprehensible input and reduces stress. Its characteristics are conducive to beginners learning, especially for young learners. Obviously, effective teaching will be combined with a variety of methods and methods. These two methods are only a set of techniques that can be compatible with other methods, so that productive teaching finally will be achieved.

\section{REFERENCES}

[1] Brown, H. D. Principles of language learning and teaching[M]. New York: Longman, 2006.

[2] Richrds, J., \& Rodgers, T. Approaches and methods in language teaching[M]. New York: Cambridge University Press, 2001.

[3] Harmer, J. The practice of English language teaching[M]. Harlow: Longman, 2007.

[4] Hall, G. Exploring English language teaching: language in action[M]. New York: Routledge,2011.

[5] Tian, D.J. The implementation of Total Physical Response in college English classrooms[J]. Overseas English, 2014:61-62.

[6] Wei, W. Brief analysis of Total Physical Response teaching method in second language teaching classrooms[J]. Journal of Tongling College, 2014, (4):124-125.

[7] Bowen, T.( n.d. ). Teaching approaches: what is audiolingual. 